reaction, a specific gravity of 1015, a minute trace of albumin, no sugar, a large deposit of amorphous and triple phosphates, and some epithelial cells. A subsequent acute attack of renal colic was the prelude to a short illness in the course of which he had much trouble with his bladder, and which terminated fatally from sudden and unexpected coma.

The details of this case are so interesting and the record of symptoms is so graphic that I hope no apology is necessary for the length of the extracts which I have quoted. The entire disappearance of phosphaturia during the time he was taking butter-milk suggests that the acids which it contains so abundantly had probably something to do with neutralising the excess of phosphates, and if this be so it raises the question whether the large quantities of buttermilk which during his craze he was tempted to drink does not convey a hint that in the use of acids in ordinary forms of neutral or alkaline phosphatic urine we perhaps err in dealing with inadequate doses.

The presence of triple phosphates in the last analysis and the co-existence of pain, heat, and straining on micturition too clearly showed that the bladder had become the seat of a calculus, most probably a rapidly accumulating mass of phosphates outside a uric acid nucleus. He died comatose and this could hardly be ascribed to the condition of either his bladder or kidney. It more closely resembled the coma so often met with in diabetes mellitus. The urine was persistently excessive in quantity but it never contained sugar. If the uric acid element in this case be left out the picture of Tessier's phosphatic diabetes is almost complete. Most of the leading features of ordinary diabetes present themselves but the urine contains as its abnormal constituent an excess of phosphates instead of sugar.

Cases of this disorder are rare, but their diagnosis is easy if due attention is given to the urine, which is always neutral or alkaline in reaction, excessive in amount, usually of low specific gravity, and loaded with phosphates often of the stellar variety. The diseases with which it is most liable to be confused are diabetes mellitus, diabetes insipidus, and chronic interstitial nephritis. The urine of diabetes mellitus contains sugar and that of interstitial nephritis albumin, so that in straightforward cases either may be readily distinguished from the urine of phosphaturia. The latter condition, however, may occur in association with either or both of the former, when the urine will be found to contain phosphates, together with sugar or albumin, or with both.

The effect upon the general health tends to be ultimately serious and the prognosis should always be guarded. The occurrence of attacks of drowsiness, the onset of emaciation, the alternation of sugar with stellar phosphates, or a permanent increase in the urea excretion are the more important points which add to the gravity of the prognosis.

Treatment is summed up, according to Ralfe, in rest and improvement of the general nutrition. Drugs seem to be of little avail in checking the undue excretion of phosphates; even opium, which is of such value in true diabetes, has no effect and is, on account of the tendency to drowsiness, not altogether free from risk. Butter-milk may be added to the daily dietary and will be found of considerable nutritive value. This case suggests that it may also possess some direct power over phosphates when these are present in marked excess.

Chesham-street, Belgrave-square, S.w.

Crerical, Medical, and General Life AssurANCE SOCIETY. - The report of this society for the year ended Jane 30 th, 1899, shows that the new assurances consisted of 810 policies, assuring $£ 641,353$, and yielding in annual premiums £21.797. Re-assurances were effected to the extent of $£ 46,000$, with annual premiums of $£ 1741$. The net new business of the year was therefore $£ 595,353$ in sums assured, yielding annual premiums of $£ 20,056$. The total premium income was $£ 293,773$, showing an increase of $£ 5448$ over last year, and the whole income of the society was raised from $£ 422,006$ to $£ 431,776$. The claims arising from the death of 235 persons, assured under 299 policies, were for the aggregate amount of $£ 239,897$. The excess of revenue over all expenditure amounted to no less than $£ 105,900$ and raised the assurance fund at the close of the year to $£ 3,590,305$. Three vacancies occurred in the board of directors caused by the death of Sir John Mowbray (the chairman) and the resignation of Lord Curzon and Lord Lister. Sir Thomas Smith, F.R.C.S. Eng., was elected in L rrd Lister's place.

\section{A CASE OF IRREDUCIBLE DISLOCATION AT THE ELBOW.}

BY R. HAMILTON RUSSELL, F.R.C.S. ENG,

SURGEON TO THE MELBOURNE HOSPITAL FOR SICK GHILDREN.

ON June 27th last a little boy, aged eight years, while playing at football fell with the left arm twisted under him and sustained a dislocation of both bones of the forearm backwards at the elbow. He was attended by Dr. Loosli of this city, who was at once struck by certain peculiarities in the cass; he also found that all efforts at reduction, even under chloroform, were of no avail, and asked me to see the patient with him.

On examination the fact of dislocation backwards of both bones was very obvious, but there were unusual features which, as the accident is one that, so far as I can ascertain, is now recorded for the first time, I will describe with some minuteness. First, the arm was markedly straighter than usual-so nearly straight, in fact, that it had been found possible to put the limb up somewhat loosely in straight cardboard splints ; secondly, there was an absence of the usual marked fixity of the arm, so that the forearm could be moved through a considerable angle but could hardly be made to approach so near to a right angle with the humerus as is usual in such a dislocation; thirdly, on attempting reduction, the sensation imparted to me was quite novel: the forearm yielded to the pull quite easily, and the deformity could be very nearly reduced but not quite, while directly the force was withdrawn the bones sprang back into their false position with a kind of elastic rebound. There was also occasional slight crepitus. I was unable at the time to make a correct diagnosis of the exact anatomical nature of the injury which produced these phenomena, but I advised, with Dr. Loosli's concurrence, an operation which was undertaken the next day.

Through a longitudinal incision over the extensor aspect of the joint the triceps and aponeurotic investment of the joints were divided and the interior of the articulation was exposed to view. It was then fonnd that the interior was occupied by a mass of muscle which further investigation made evident as the brachialis anticus. The internal epicondyle was separated, which explained the slight crepitus during examination. 'I he humerus at the time of the injury had pushed its way through the anterior ligament of the joint and passing to the outer side of the brachialis anticus had become lodged on the front of that muscle; so that when viewed through the operation wound the muscle lay strapped over the back of the lower end of the humerus and pinched tightly between that bone and the coronoid process of the ulna. It was necessary to divide a portion of the displaced muscle, and when that was done a strong curved spatula was passed between the remainder of the muscle and the bone and the humerus was easily pulled into place. The divided triceps was then sutured, the skin wound was completely closed, and the arm was put up straight in a stiff bandage. Six days later the bandage was taken off for the removal of the stitches. The wound was quite healed, and the little boy was able to bend his arm without assistance to near the right angle, in which position it was put up again in plaster-of-Paris for a further fortnight. Three weeks from the operation all apparatus was removed, but the child was directed to wear a sling for one week more. with permission, however, to take the arm out to use it when so inclined, but to return it to the sling when not using it; this was out of consideration for the partially divided brachialis anticus muscle. No passive motion was performed, although the elbow remained very stiff for some weeks. When last seen, five months after the accident, however, the movement had all returned and the result was perfect as to the utility of the arm, but on close inspection during flexion of the arm I had reason to thirk that the brachialis anticus had never completely recovered and that the other muscles passing from the condyles to the forearm and wrist were called upon for a somewhat larger share than usual in the production of flexion at the elbow. This seemed, however, to make no difference, as the child was able to play cricket and other games, and there was no perceptible weakness or defect in the limb.

Melbourne. 


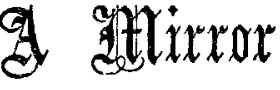 \\ or}

\section{HOSPITAL PRACTICE, BRITISH AND FOREIGN.}

Nulla autem est alia pro certo noscendi via, nisi quamplurimas of morborum et dissectionum historias, tum aliorum tum proprias collectas habere, et inter se comparare.-MorgagNI De Sed. et Caus. Morb., lib. iv. Procmium.

\section{HOSPITAL FOR SICK CHILDREN, GREAT ORMOND-STREET.}

A CASE OF CHRONIC INTESTINAL OBSTRUCTION; NECROPSY. (Under the care of Dr. D. B. LEES.)

INTESTINAL obstruction is a rare but very important complication of appendicitis. It is specially likely to occur in cases in which localised abscesses have formed and Hawkins ${ }^{1}$ describes four deaths as due to this cause in ten fatal cases of local abscess; these are generally acute cases. Obstruction of the intestine, when chronic in character, if due to appendicitis, is more likely to result from matting together of the bowel ${ }^{2}$ as in the case recorded below. In this instance it is not improbable that tuberculous disease of the appendix was the cause of the adhesions. Fitz ${ }^{3}$ met with eight cases of perforation of the appendix resulting from tuberculosis in 257 cases of appendicitis. For the notes of the case we are indebted to Dr. Hugh Thursfield, medical registrar and pathologist.

A boy, aged two and a half years, was admitted into the Hospital for Sick Children, Great Ormond-street, under the care of Dr. D. B. Lees, at the end of June, 1899. He was brought to the hospital on account of constipation and was treated in the out-patient department. The constipation was followed by a bad attack of diarrhoea for which he was made an in-patient. The history given by his mother was that till the age of 18 months he was a healthy child, but he then began to suffer from attacks of diarrhoea. Three months later his stomach was noticed to be getting larger and the diarrhcea was now accompanied by abdominal pain. He was treated by a medical man and improved, but about Easter, 1899 , he began to have attacks of abdominal pain in which the stomach was, as hiz mother said, "drawn up in cords"" $\mathrm{He}$ twice passed blood by the rectum and vomited dark-brown fluid. He went to the country and improved for a time, but the abdominal troubles recurred and he was taken to the hospital. As well as could be ascertained the family history and the surroundings of the child were fairly good, though his mother's father was stated to have died from "consumption."

On admission the child was very thin and fretful but bad no fever and at first no diarrhcea; his appetite was fairly good and he did not appear to be very ill. The heart and lungs were apparently sound, but the abdomen was enlarged; there was visible peristalsis, and on the right side rather low down there was a mass which felt like a mass of enlarged glands. From time to time this mass could be felt in slightly different positions, the most constant being just to the right of, and below, the umbilicus. At first the child improved greatly, but at the end of July diarrhcea with some fever set in and he began to lose ground. The motions were pale, slimy, and drab-coloured. There was never any blood. In August and September he had several severe attacks of abdominal pain, which were accompanied by visible peristalsis, the small intestines being especially concerned. The diagnosis lay between enlarged tuberculous glands with matting tcgether of coils of intestine and a chronic intussusception of the bowel. In the hope of relievin $x$ the obstruction laparotomy was performed by $\mathrm{Mr}$. T. H. Kellock on Sept. 28th. He felt some large glands and saw a few yellow tubercles on the peritoneum; some adherent coils of intestine were separated and a small band of fibrous tissue was dirided. After the operation the child was completely relieved of the attacks of abdominal pain but his condition otherwise remained unaltered. The diarrhœa recurred, he began to have an intermittent temperature, and gradually sank, and died on Oct. 12th.

I Diseases of the Vermiform Appendix, p. 94 2 Mynter: Appendicitis, p. 89

3 American Journal of the Medical Sciences, October, 1888.
Neoropsy.-The post-mortem examination was made 48 hours atter death. In the head and thorax no abnormal condition was observed. On the parietal peritoneum in a few places there were small scattered granular tubercles but no general tuberculous peritonitis was present. On the right side the liver was bound to the abdominal wall by dense adhesions. The lowest part of its right lobe was involved in a mass which consisted of liver, intestine, peritoneum, and mesentery and they were so bound together that even careful dissection could scarcely separate the various parts. This mass lay to the right of, and rather below, the umbilicus, lying, in fact, orer the lower half of the right kidney. On dissecting the mass the appendix was found lying in a line pointing vertically upwards behind the colon. Its tip, however, on the inner side of the colon was adherent to the lowest part of the right lobe of the liver; and matted round this point were loops of small intestine, the mesentery, the ascending colon, and several large glands, in one of which there was a caseous focus. In two places at least there was a fistulous communication between the appendix and the small intestine which was much ulcerated. The ascending colon showed very little ulceration and no fistula was found. On opening the loop of small intestine two small brownish bodies fell out which resembled the kernel of some fruit, such as an apricot. The small intestine above the portion involved in the tumour had its walls remarkably thickened and hypertrophied. The descending colon was the site of very numerous small ulcerations, some of which showed tubercles on the peritoneal surface, and all were transverse to the gut and had edges slightly raised and much undermined. The lowest portion of the sigmoid flexure was caught up and fixed by strong adhesions to the tumour above. The spleen showed a few granular tubercles and one small caseous patch. The mesenteric glands were rather larger than normal and in one of these there was a focus of caseation, but no mass of large glands was found. The glands elsewhere were normal.

Remarks by Dr. LEES. - An accurate diagnosis of this case may fairly be said to have been impossible. The mass felt on admission was thought to be composed of caseous glands and intestine matted together by a chronic tuberculous process. The history given by the mother seemed to be in accord with this view, the blood passed on two occasions per rectum and the diarrhœea being ascribed to tuberculous ulcerations of the bowel. The attacks of abdominal pain and the visible peristalsis were ascribed to the obstruction caused by the implication of the intestine in the mass which could be felt. But when the peristalsis became extreme, coils of small intestine pushing forward the abdominal wall in prominent ridges during the attacks of pain, it was determined to try whether any relief could be given by operation. The laparotomy revealed adherent intestine, enlarged glands, and some tubercle. As much separation of the adhesions was effected as seemed possible without incurring the risk of rupture of the bowel. But the facts that a coil of small intestine was adherent to a diseased appendix vermiformis, with two communications into it, that the tip of the appendix was adherent to the liver, and that the adherent bowel contained two foreign bodies, were revealed only by the necropsy. It may be added that the foreign bodies were precisely similar to one another, being oval in shape and quite unlike the "fæcal concretions" which often perforate the appendix.

Remarks by Dr. ThURSFIELD.-Pathologically the points of interest seem to me to be the unusual position of the appendix and the question of the sequence of events-that is, whether the tuberculous infection preceded and determined the formation of the adhesions between the liver and appendix or whether the tuberculous infection took place in a part of the intestine which was already the seat of inflammation. I do not think that it is possible to advance beyond speculation, but probability appears to me to point to the first solution. 'The presence of the foreign bodies I regard as accidental and quite recent.

\section{BEDFORD COUNTY HOSPITAL.}

A CASE OF SUPPURATIVE APPENDICITIS WITH SECONDARY LIVER ABSCESSES.

(Under the care of Mr. W. GIFFond NASH.)

ABscess of the liver occurring in the course of appen. dicitis is nearly always the result of a septic thrombosis or of a pylepblebitis, but, as in the case here recorded, it may 